December 1998 • NREL/CP-520-25614

\title{
Accelerated Durability Testing of Electrochromic Windows
}

C.E. Tracy, J.G. Zhang, D.K. Benson, A.W. Czanderna, and S.K. Deb

Presented at the International Meeting on Electrochromism

London, UK

September 7-9, 1998

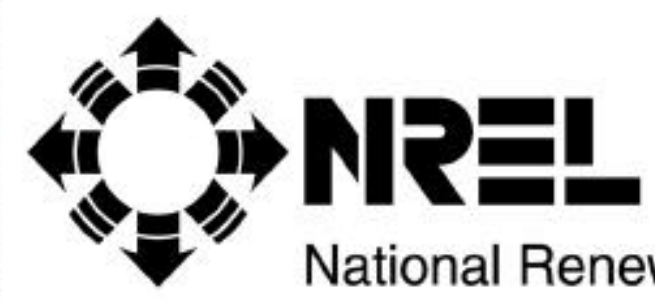

National Renewable Energy Laboratory

1617 Cole Boulevard

Golden, Colorado 80401-3393

NREL is a U.S. Department of Energy Laboratory

Operated by Midwest Research Institute - Battelle $\bullet$ Bechtel

Contract No. DE-AC.36-98-G010337 


\section{NOTICE}

This report was prepared as an account of work sponsored by an agency of the United States government. Neither the United States government nor any agency thereof, nor any of their employees, makes any warranty, express or implied, or assumes any legal liability or responsibility for the accuracy, completeness, or usefulness of any information, apparatus, product, or process disclosed, or represents that its use would not infringe privately owned rights. Reference herein to any specific commercial product, process, or service by trade name, trademark, manufacturer, or otherwise does not necessarily constitute or imply its endorsement, recommendation, or favoring by the United States government or any agency thereof. The views and opinions of authors expressed herein do not necessarily state or reflect those of the United States government or any agency thereof.

Available to DOE and DOE contractors from:

Office of Scientific and Technical Information (OSTI)

P.O. Box 62

Oak Ridge, TN 37831

Prices available by calling 423-576-8401

Available to the public from:

National Technical Information Service (NTIS)

U.S. Department of Commerce

5285 Port Royal Road

Springfield, VA 22161

703-605-6000 or 800-553-6847

or

DOE Information Bridge

http://www.doe.gov/bridge/home.html

Printed on paper containing at least $50 \%$ wastepaper, including $20 \%$ postconsumer waste 


\begin{abstract}
Prototype electrochromic windows made by several different U.S. companies have been tested in our laboratory for their long-term durability. Samples were subjected to alternate coloring and bleaching voltage cycles while exposed to simulated on 1-sun irradiance in a temperature-controlled environmental chamber with low relative humidity. The samples inside the chamber were tested under a matrix of different conditions. These conditions include: cycling at different temperatures $\left(65^{\circ} \mathrm{C}, 85^{\circ} \mathrm{C}\right.$, and $\left.107^{\circ} \mathrm{C}\right)$ under the irradiance, cycling versus no-cycling under the same irradiance and temperature, testing with different voltage waveforms and duty cycles with the same irradiance and temperature, cycling under various filtered irradiance intensities, and simple thermal exposure with no irradiance or cycling. The electrooptical characteristics of the samples were measured between 350 and 1,100 nm every 4,000 cycles for up to 20,000 cycles. Photographs of the samples were taken periodically with a digital camera to record cosmetic defects, the extent of residual coloration, and overall coloration and bleaching uniformity of the samples. Our results indicate that the most important cause of degradation is the combination of continuous cycling, elevated temperature, and irradiance. The relative importance of these variables, when considered synergistically or separately, depends on the particular device materials and design.
\end{abstract}

Key words: electrochromic windows, accelerated life testing, durability, energy savings, degradation factors. 


\section{INTRODUCTION}

The worldwide effort to develop electrochromic (EC) devices has increased rapidly in recent years, and many companies are in the process of commercializing EC devices for window applications [1-6]. In residential buildings, a crucial requirement for EC window applications is that its lifetime be more than 20 years. Because it is impractical to wait for results from realtime testing, considerable work has been directed toward examining the durability of EC windows by using accelerated life testing (ACLT) [7-11]. In addition to the choice of an appropriate EC window design, another important purpose of these activities is to elucidate the degradation mechanisms in these windows such that manufacturers can modify their design and extend the lifetime of the product. In this paper, we report on a systematic study of the factors affecting the degradation of prototype EC windows. Devices constructed by several manufacturers have been subjected to ACLT in our laboratory for their long-term durability. Samples were exposed to a matrix of different testing conditions and cycled for more than 20,000 times. Factors that contribute to the degradation of the devices are discussed.

\section{EXPERIMENTAL}

\subsection{Measurement System}

Small $7.6 \mathrm{~cm} \times 7.6 \mathrm{~cm}$ (3" x 3") prototype EC windows received from different manufacturers were placed in a SolarClimatic 1600 (Atlas Electric Devices, Inc.) This system used two 4000-W metal halide lamp as the light source with an irradiance of $1000 \mathrm{~W} / \mathrm{m}^{2}$ (1 sun) 
across the horizontal test plan on which the samples were laid. The spectral power distribution of the lamps in the range of 280-3000 nm satisfies the requirement of CIE (Pub. No. 85, Table 4). The output stability of the source was within $\pm 1 \%$, and the working volume of the system chamber is $2.9 \mathrm{~m} \times 0.89 \mathrm{~m} \times 2 \mathrm{~m}(\mathrm{~W} \times \mathrm{D} \times \mathrm{H})$. The lateral uniformity of the irradiance in the area occupied by the EC devices was $\pm 4 \%$. The relative humidity $(\mathrm{RH})$ in the chamber was about $20 \%$, and temperature of the chamber could be controlled at $-10^{\circ} \mathrm{C}$ to $+90^{\circ} \mathrm{C}$. More detail about characterizing ACLT chambers is available [8]. During our normal operations, the system air temperature was set at $33^{\circ} \mathrm{C}$ to produce an average illuminated sample temperature of $65^{\circ} \mathrm{C}$ without auxiliary heating. Samples tested at elevated temperatures within the same chamber were placed on top of temperature-controlled hot plates constructed of rectangular aluminum sheets ( $\sim 3 \mathrm{~mm}$ thick) bonded to silicone heater pads. The control temperatures of the hot plates were set at $85^{\circ} \mathrm{C}$ and $113^{\circ} \mathrm{C}$ to achieve nominal sample temperatures of $85^{\circ} \mathrm{C}$ and $107^{\circ} \mathrm{C}$, respectively. The sample temperature fluctuated within $\pm 3^{\circ} \mathrm{C}$ relative to the desired nominal temperature because of changing absorption properties throughout the coloration cycles of the EC devices. Samples were exposed to five series of 4000 cycle tests under the 1-sun irradiance in the environmental chamber. Each series of 4000 cycles lasted about $100 \mathrm{~h}$.

The coloring and bleaching processes of the EC devices were controlled and recorded by a 48-channel potentiostat (Arbin Battery Testing system). The transient voltage behavior of an EC window tested with this system was measured with the aid of a digital storage oscilloscope and a digital camera. The polarity of step voltage applied to the device was changed every minute. The sampling rate of the oscilloscope was $1 \mathrm{~ms} /$ point. The optical properties of the samples were measured using a photodiode array spectraphotometer (Ocean Optics, Model 
PCD1000). The specific description of the optical measurement system has been published elsewhere [8] .

\subsection{Measurement Procedure}

Electro-optical properties of all samples were first characterized at room temperature $\left(22^{\circ} \mathrm{C}\right)$ using the switching voltage profiles recommended by the device manufacturers. The samples were then separated into several groups and characterized at different temperatures $\left(65^{\circ} \mathrm{C}, 85^{\circ} \mathrm{C}\right.$, and $\left.107^{\circ} \mathrm{C}\right)$ in a convection oven. A thermocouple was attached to the top surface of the sample with aluminum tape $\left(\sim 8 \mathrm{~mm}^{2}\right.$ patch $)$ to measure the sample temperature. The coloring and bleaching times were adjusted to obtain a contrast ratio (CR, the ratio of transmittances in the bleached and colored states at $550 \mathrm{~nm}$ ) of at least 5 for all samples at specified temperatures. The switching parameters obtained in these initial characterizations were used to set up long-term cycling programs to control the multichannel potentiostat. The programs were tested first using 30-ohm resistors to mimic the EC samples inside of the testing chamber. After all samples were placed inside the environmental chamber and properly connected, they were colored and bleached using the room-temperature testing programs to ensure that all electrical connections, thermocouple connections, and control programs functioned properly. The chamber air temperature was then stabilized at the set-point temperature (e.g., $33^{\circ} \mathrm{C}$ to insure nominal sample temperature of $65^{\circ} \mathrm{C}$ under illumination). Control temperatures for the samples on the hot plates were then adjusted to achieve nominal temperatures of $85^{\circ} \mathrm{C}$ and $107^{\circ} \mathrm{C}$. 
Prototype EC devices received from the manufacturers were tested under a matrix of conditions as shown in Table 1. Samples held at a nominal temperature of $65^{\circ} \mathrm{C}$ were subjected to six different conditions: standard, duty cycle, waveform, no cycling and with irradiance, no cycling and no irradiance, and with four neutral-density optical filters. Samples supplied with auxiliary heating to achieve nominal temperature of $85^{\circ} \mathrm{C}$ and $107^{\circ} \mathrm{C}$ were tested using only three conditions: standard, no cycling with irradiance, and no cycling without irradiance. Results obtained with respect to the three temperatures could be analyzed and compared for only these three conditions. For samples held at $65^{\circ} \mathrm{C}$, the "standard" condition in Table 1 means that the samples were tested under 1-sun irradiance using the voltage profile determined by the initial electro-optical characterization at $65^{\circ} \mathrm{C}$. Figure 1 shows typical voltage and current profiles of an EC window tested under the standard condition. The "duty cycle" condition in Table 1 means that the samples were tested under 1 -sun illumination at $65^{\circ} \mathrm{C}$, but every voltage pulse was followed by a relaxation period (open circuit) for the same time as the time for coloring or bleaching. Figure 2 shows typical voltage and current profiles of an EC window tested using the duty-cycle condition. Similarly, the "waveform" condition in Table 1 means that the samples were tested under 1-sun illumination at $65^{\circ} \mathrm{C}$, but using a voltage ramp of $0.1 \mathrm{~V} / \mathrm{sec}$ instead of the step voltage as adopted in the standard condition. Figure 3 shows typical voltage and current profiles of an EC window tested using the waveform condition. One sample from each temperature group was tested under 1-sun illumination with no voltage applied (i.e., "no cycles and with irradiance" condition as shown in Table 1). For the sample tested under the "filter" condition, a special filter holder was placed on the top of the sample. The filter area was the same as that of the sample, but it was separated into four parts that could hold four different 
neutral density filters with a visible transmittance of $91 \%, 79 \%, 50 \%$, and $25 \%$, respectively. The voltage profile used for this sample was the same as used for the standard condition.

For the samples tested at $85^{\circ} \mathrm{C}$ and $107^{\circ} \mathrm{C}$, the "standard" condition defines that the samples were tested under 1-sun illumination using the voltage profile determined by the initial electro-optical characterization at $85^{\circ} \mathrm{C}$ and $107^{\circ} \mathrm{C}$, respectively. The samples tested using conditions of the "no cycles and with irradiance" were placed on top of the same hot plate as the samples under the standard condition, but no voltage was applied. The samples tested under the condition of no cycles and no irradiance were placed on similar temperature-controlled hot plates outside of the Atlas 1600 for a time corresponding to each 4000 cycles of testing in the chamber. The set points of the hot plates were $81^{\circ} \mathrm{C}, 98^{\circ} \mathrm{C}$, and $125^{\circ} \mathrm{C}$ to achieve nominal sample temperatures of $65^{\circ} \mathrm{C}, 85^{\circ} \mathrm{C}$, and $107^{\circ} \mathrm{C}$, respectively. Finally, one sample from each temperature group was reserved as a control sample in which no degradation under roomtemperature storage is expected, but was monitored.

For each 4000 cycles, all samples were exposed to the same amount ( 100 h) of 1-sun irradiance (and/or elevated temperature) regardless of the timing of their electrical protocol for color and bleach cycles. After each of the five 4000-cycle test series, all samples were optically characterized and visual observations of cosmetic defects were noted. Digital photographs were taken for the more highly degraded samples. Optical data (as contrast ratios, the transmittance in the bleached states) and cosmetic defect data were then compiled into tabular form using the format illustrated by Table 1 . 


\section{RESULTS AND DISCUSSION}

It is well known that EC windows are very sensitive to over-voltage spikes. Some devices may be damaged even when subjected to a transient voltage spike that can be present in some voltage supplies. Therefore, we examined the transient electrical behavior of the multichannel potentiostat while delivering step-voltage pulses to the EC devices. Digital oscilloscope traces of the transient electrical behavior of an EC device during the coloring and bleaching processes are shown in Figs. 4(a) and 4(b), respectively, for which the sampling rate is $1 \mathrm{~ms} /$ point. No over-voltage spike can be observed in these figures. If, on the other hand, we replaced the EC window sample with a 10,000-ohm resistor, a distinct over-voltage spike could be observed during first the first $50 \mathrm{~ms}$ of the voltage pulse; over-voltage pulses of more than 100\% could be recorded as shown in Fig. 5. These results are not surprising because EC devices, unlike simple resistors, usually have a small resistance and a large capacitance, which manifests itself in a large damping constant for the system (combination of the potentiostat and the device). The results of Fig. 4 verify that our electrical testing system delivered smooth voltage pulses to the EC devices.

Long-term cycling results indicate that the degradation of EC windows is the result of the combined effects of elevated temperature, irradiance, and continuous cycling. The relative importance of these variables, when considered synergistically or separately, depends on the materials of construction and design of the particular device. In some cases, simulated solar irradiance was the principal factor that contributed to a residual coloration in EC windows. The bleach-state transmittances of the samples tested at elevated temperature but with no cycling 
were very close to the original transmission characteristics of the control samples. In other cases, temperature was the most detrimental factor and resulted in a large degradation of the EC devices even without illumination or cycling.

After exposing the samples to 20,000 cycles of testing, samples in all categories at all temperatures exhibited different degrees of degradation. The types of cosmetic defects in these devices included: color streaks in the bleached state or bleach spots in the colored state, nonuniform coloration, and residual coloration in the bleached state. The appearance of cosmetic defects and the decline of contrast ratios were accelerated at higher temperatures. The samples cycled at high temperature, but without illumination, exhibited different residual colorations when compared with those cycled at the same temperature with illumination. These experiments indicate that different degradation mechanisms in the EC windows may result from using illumination and temperature or just temperature (both with cycling).

Results from samples tested with various neutral density filters revealed that the contrast ratio of the EC windows decreases more rapidly with illumination intensity. This reduction in the contrast ratio was predominantly the result of increasing residual coloration in the bleached state; the degree of reduction depends strongly on the configuration and materials in the device. Photographs of the first-cycle colored state taken immediately after removal from the Atlas 1600 chamber, conclusively show an increased residual coloration and decreased contrast ratio, which is a function of the transmission through the filter. The areas outside the four circular filtered regions, which were masked by the aluminum filter holder, displayed no residual coloration when cycled repeatedly from a bleached state to a deeply colored state. 
Indeed, in other samples that exhibited a residual brown coloration, the areas under the aluminum tape used to secure the thermocouple did not exhibit a residual color and also darkened more during coloring than the surrounding area. Thus, the intensity of a brown residual coloration was directly proportional to the intensity of light reaching the sample. Apparently, electrical cycling is another necessary requirement for degradation because uncycled, illuminated samples never exhibited a brown residual color.

Selected samples were shielded with 1-cm square patches of UV-absorbing plastic sheet in one corner of the selected devices. This UV barrier is a commercially available polycarbonate product from GE plastics (Product \#HP92W). Visual observation of these samples showed both a deeper color under the UV barrier patch in the colored state and less residual brown coloration in the bleached state, or both. Areas under the aluminum tape patches (used to secure the thermocouple) showed this same tendency, but with a much more pronounced effect. Based on the above results, it is apparent that not only UV lights but also visible light above $400 \mathrm{~nm}$ contribute to the degradation of the contrast ratio and the formation of residual coloration. Finally, samples tested using the "duty cycle" and "waveform" conditions showed no conclusive trends or differences when compared with other samples cycled at $65^{\circ} \mathrm{C}$ under standard conditions.

In summary, after exposing the prototype EC windows to 20,000 cycles of testing using various conditions, samples in all categories at all temperatures exhibited different kinds and degrees of degradation. The two basic types of degradation are: (1) a decreased contrast ratio, and (2) an increase in the number of cosmetic defects. The decline in the contrast ratio of the 
device at $550 \mathrm{~nm}$ results from a decreased transmittance in the bleached state, an increased transmittance in the colored state, or a combination of both. Cosmetic defects include color streaks in the bleached state or bleached spots in the colored state, non-uniform coloration, and residual coloration in the bleached state. Of the various testing conditions, temperature and illumination are the most predominant factors that contribute to the degradation of the EC window devices. Both UV and visible light with wavelengths above $400 \mathrm{~nm}$ contribute to the degradation of the contrast ratio and the formation of residual coloration in the bleached state. The phenomenon of brown residual coloration requires both electrical cycling and illumination. The relative importance of these factors, when considered synergistically or separately, depends on the materials of construction and design of the particular device. Manufacturers have made great strides in producing more durable EC device structures. However, further improvements are required to provide the durability necessary to withstand in-service environmental stresses for lifetimes of 20 years or more.

\section{ACKNOWLEGEMENTS}

The authors thank Dr. Anoop Agrawal, Donnelly Corp.; Dr. N. Sbar, SAGE Electrochromics, and Dr. N. O'Brien, OCLI, for providing the EC windows and for technical discussions. We are also grateful to Mr. Jim Pruett of NREL for the operation and maintenance of the Atlas 1600 and the XR-260. This work was supported by the U.S. Department of Energy under contract no. DE-AC36-83CH10093. 


\section{REFERENCES}

1. C.G. Granqvist, "Handbook of Inorganic Electrochromic Materials," Elsevier, New York (1995).

2. S.K. Deb, Solar Energy Materials and Solar Cells, 25 (1992) 327.

3. C.M. Lampert and C.G. Granqvist, in Large area Chromogenics: Materials and Devices for Transmittance Control, SPIE IS4 (1990) 2.

4. R.B. Goldner, F. O. Amtz, G. Berera, T. E. Haas, G. Wei, K.K. Wong, P.C. Yu, Solid State Ionics, 53-56 (1992) 617.

5. P.V. Ashrit, K. Benaissa, G. Bader, SPIE 1728 (1992) 232.

6. C. M. Lampert, Solar Energy Materials and Solar Cells, 52 (1998) 207.

7. A.W. Czanderna and C.M. Lampert, Evaluation Criteria and Test Methods for Electrochromic Windows, SERI/TP-255-3537 (1990), National Renewable Energy Laboratory, Golden, CO, U.S.A.

8. A.W. Czanderna, J.-G. Zhang, C. E. Tracy, D. K. Benson, and S. K. Deb, in "Optical Materials Technology for Energy Efficiency and Solar Energy Conversion XV, ed. By C.M. Lampert, C.G. Granqvist, M. Gratzel, and S.K. Satyen, SPIE vol. 3138, 68 (1997).

9. C. M. Lampert, A. Agrawal, A. Baertlien, and J. Nagai, Solar Eenrgy Materials and Solar Cells, In press. 
10. N. Sbar, M. Badding, R. Budziak, K. Cortez, L. Laby, L. Michalski, T. Ngo, S. Schulz, K. Urbanik, Solar Energy Materials and Solar Cells, In press

11. A.W. Czanderna, D. K. Benson, G. J. Jorgensen, J.-G. Zhang, C. E. Tracy, and S. K. Deb, Solar Energy Materials and Solar Cells, In press. 
Table 1. Matrix of Testing Conditions for Each Set of EC Devices

\begin{tabular}{|c|c|c|c|c|c|c|c|c|c|}
\hline \multirow{2}{*}{$\begin{array}{c}\text { Control } \\
\text { Temperature } \\
\left({ }^{\circ} \mathrm{C}\right)\end{array}$} & & & \multirow{2}{*}{$\begin{array}{c}\text { Actual } \\
\text { Sample } \\
\text { Temperature } \\
\left({ }^{\circ} \mathrm{C}\right)\end{array}$} & \multicolumn{6}{|c|}{ Contrast ratio (or Cosmetic Defects noted) } \\
\hline & & & & Initial & $\begin{array}{l}4000 \\
\text { cycles }\end{array}$ & $\begin{array}{l}8000 \\
\text { cycles }\end{array}$ & $\begin{array}{l}12,000 \\
\text { cycles }\end{array}$ & $\begin{array}{l}16,000 \\
\text { cycles }\end{array}$ & $\begin{array}{l}20,000 \\
\text { cycles }\end{array}$ \\
\hline \multirow[t]{9}{*}{$65^{\circ} \mathrm{C}$} & \multicolumn{2}{|c|}{ Standard } & & & & & & & \\
\hline & \multicolumn{2}{|c|}{ Duty Cycle } & & & & & & & \\
\hline & \multicolumn{2}{|c|}{ Waveform } & & & & & & & \\
\hline & \multicolumn{2}{|c|}{$\begin{array}{l}\text { No cycles with } \\
\text { irradiance }\end{array}$} & & & & & & & \\
\hline & \multicolumn{2}{|c|}{$\begin{array}{l}\text { No cycles and } \\
\text { no irradiance }\end{array}$} & & & & & & & \\
\hline & Filters & $91 \% *$ & & & & & & & \\
\hline & & $79 \% *$ & & & & & & & \\
\hline & & $50 \% *$ & & & & & & & \\
\hline & & $25 \% *$ & & & & & & & \\
\hline \multirow[t]{3}{*}{$85^{\circ} \mathrm{C}$} & \multicolumn{2}{|c|}{ Standard } & & & & & & & \\
\hline & \multicolumn{2}{|c|}{$\begin{array}{l}\text { No cycles with } \\
\text { irradiance }\end{array}$} & & & & & & & \\
\hline & \multicolumn{2}{|c|}{$\begin{array}{l}\text { No cycles and } \\
\text { no irradiance }\end{array}$} & & & & & & & \\
\hline \multirow[t]{3}{*}{$107^{\circ} \mathrm{C}$} & \multicolumn{2}{|c|}{ Standard } & & & & & & & \\
\hline & \multicolumn{2}{|c|}{$\begin{array}{l}\text { No cycles with } \\
\text { irradiance }\end{array}$} & & & & & & & \\
\hline & \multicolumn{2}{|c|}{$\begin{array}{l}\text { No cycles and } \\
\text { no irradiance }\end{array}$} & & & & & & & \\
\hline $\begin{array}{l}\text { Control } \\
\text { sample }\end{array}$ & \multicolumn{2}{|c|}{$\begin{array}{l}\text { Room } \\
\text { temperature } \\
\text { storage }\end{array}$} & & & & & & & \\
\hline
\end{tabular}

* Solar-weighted transmittance. 


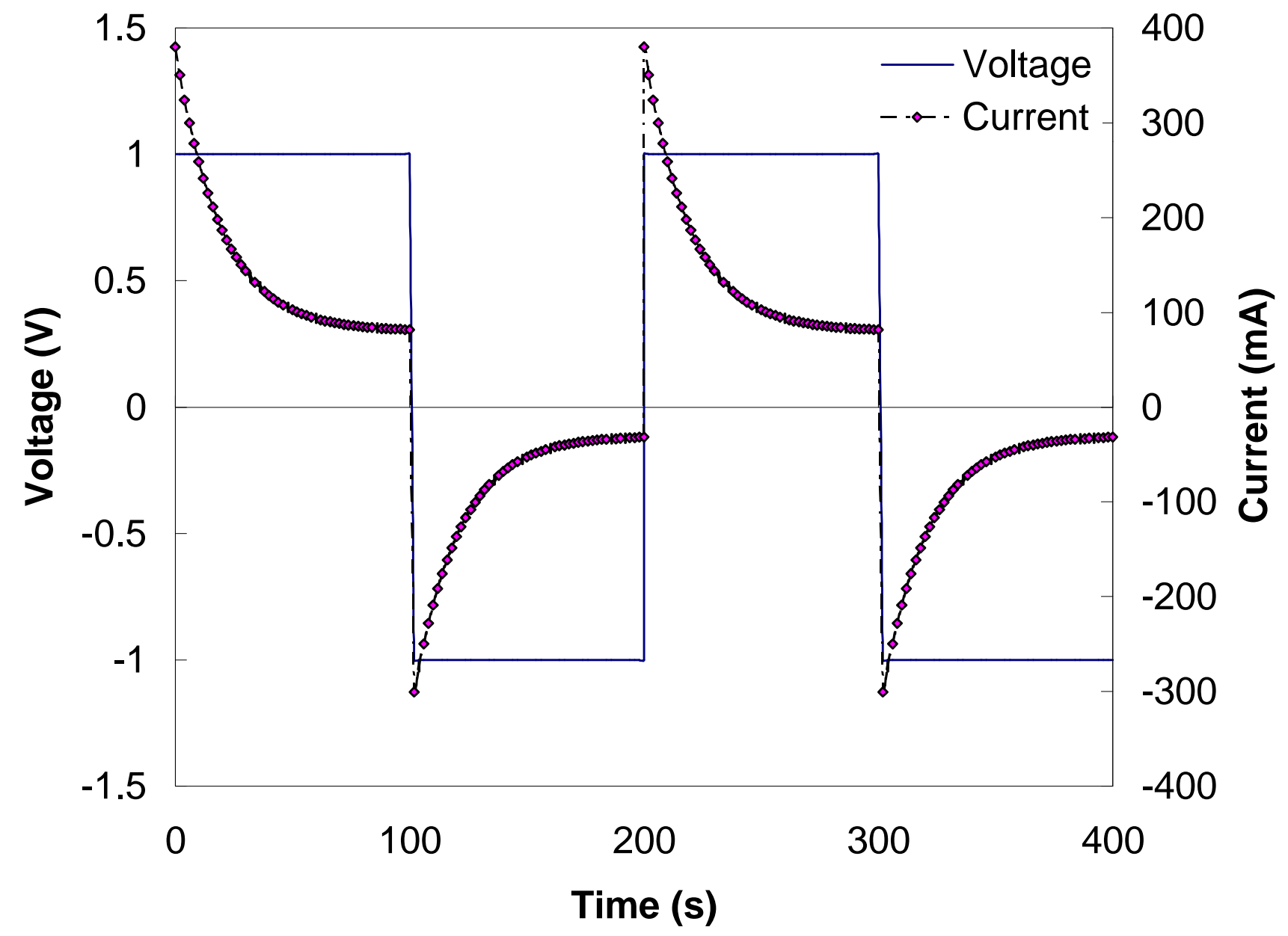

Figure 1. Typical voltage and current profiles of an EC device tested under the "standard" condition, where a step voltage was used. 


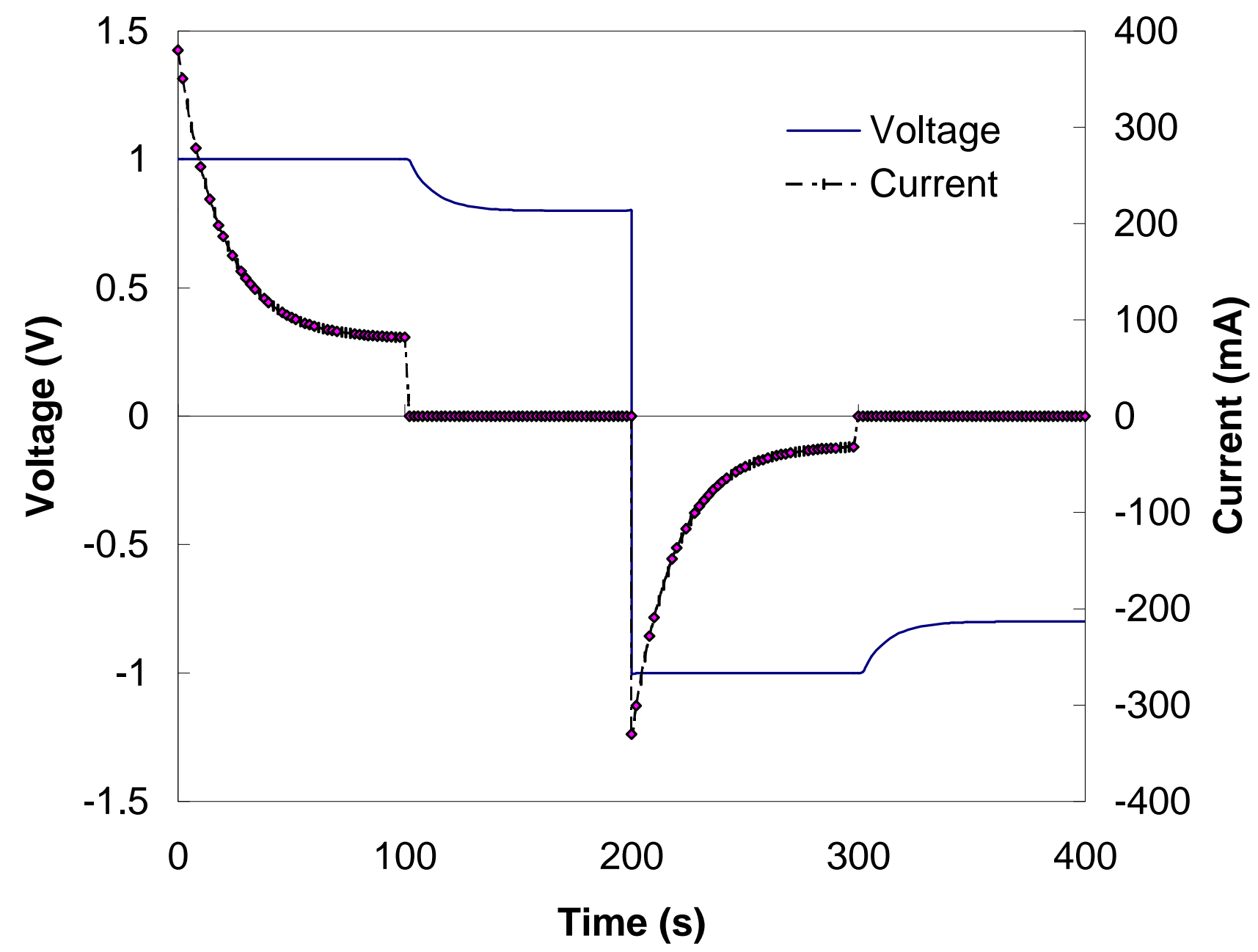

Figure 2. Typical voltage and current profiles of an EC device tested under the "duty cycle" condition, where a voltage relaxation period (open circuit) of equal time was used after each voltage pulse. 


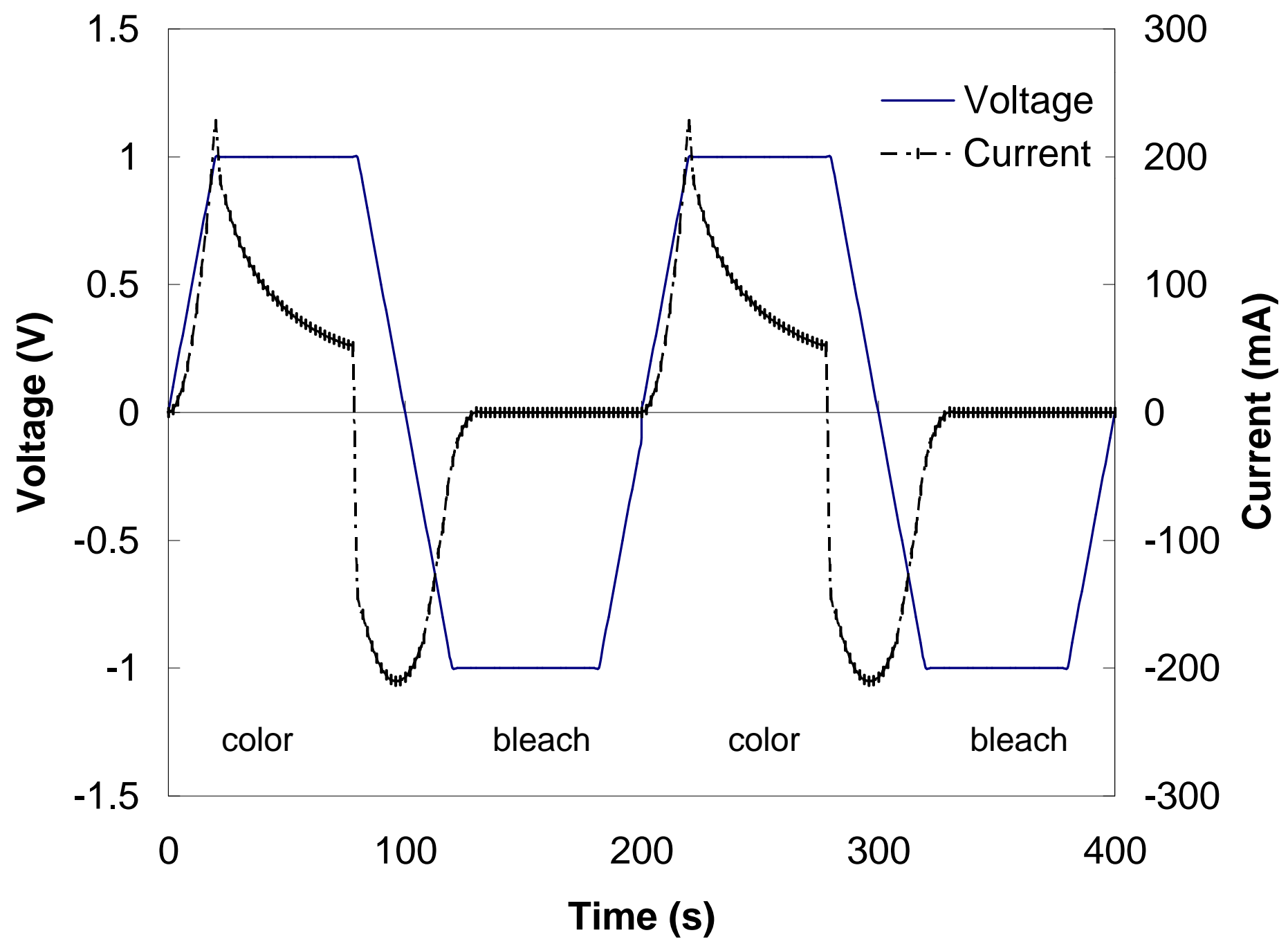

Figure 3. Typical voltage and current profiles of an EC device tested using a trapezoidal waveform in which a voltage ramp of $0.1 \mathrm{~V} / \mathrm{s}$ is used instead of a step voltage. 


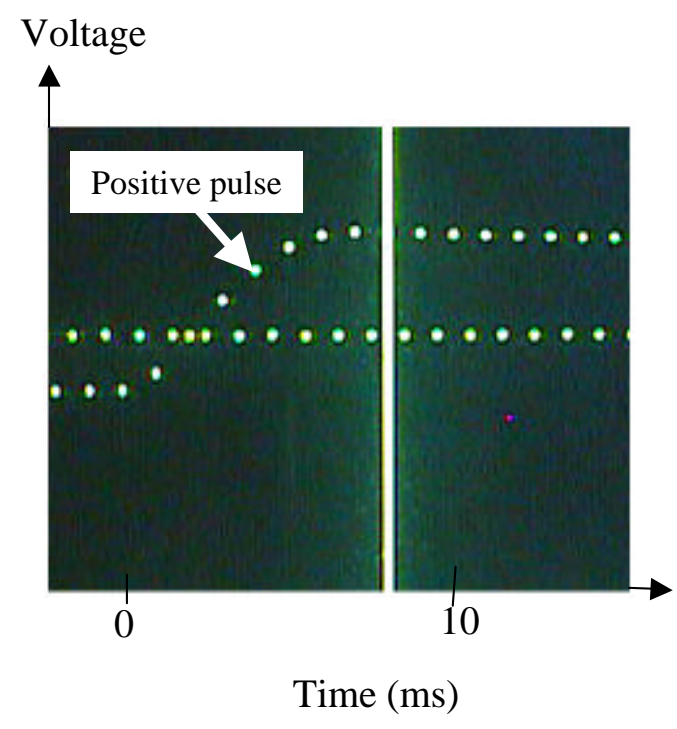

(a)

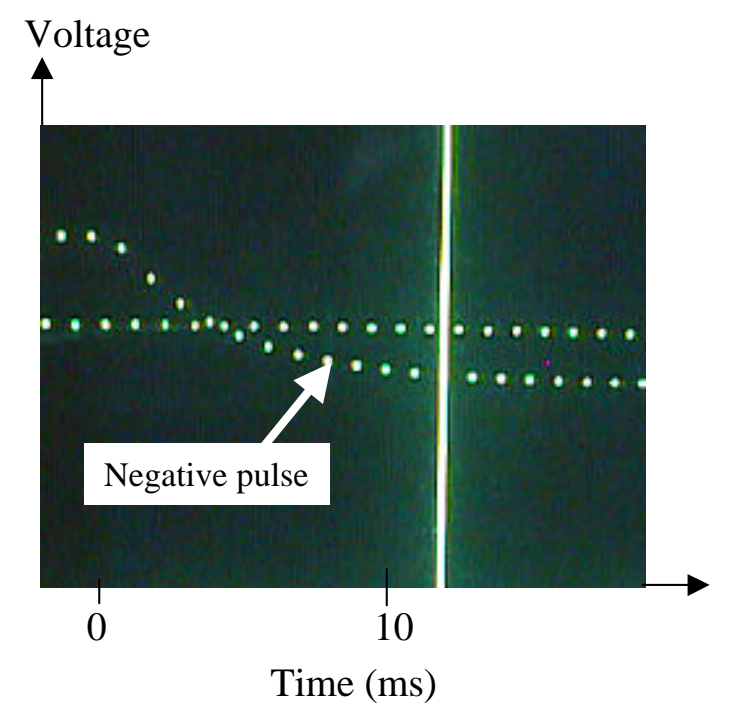

(b)

Figure 4. Transient behavior of the voltage applied to an EC device for which the sampling rate is $1 \mathrm{~ms} /$ point: (a) coloring process; (b) bleaching process. No overshoot voltage spike is observed in these oscilloscope photographs. 


\section{Voltage}

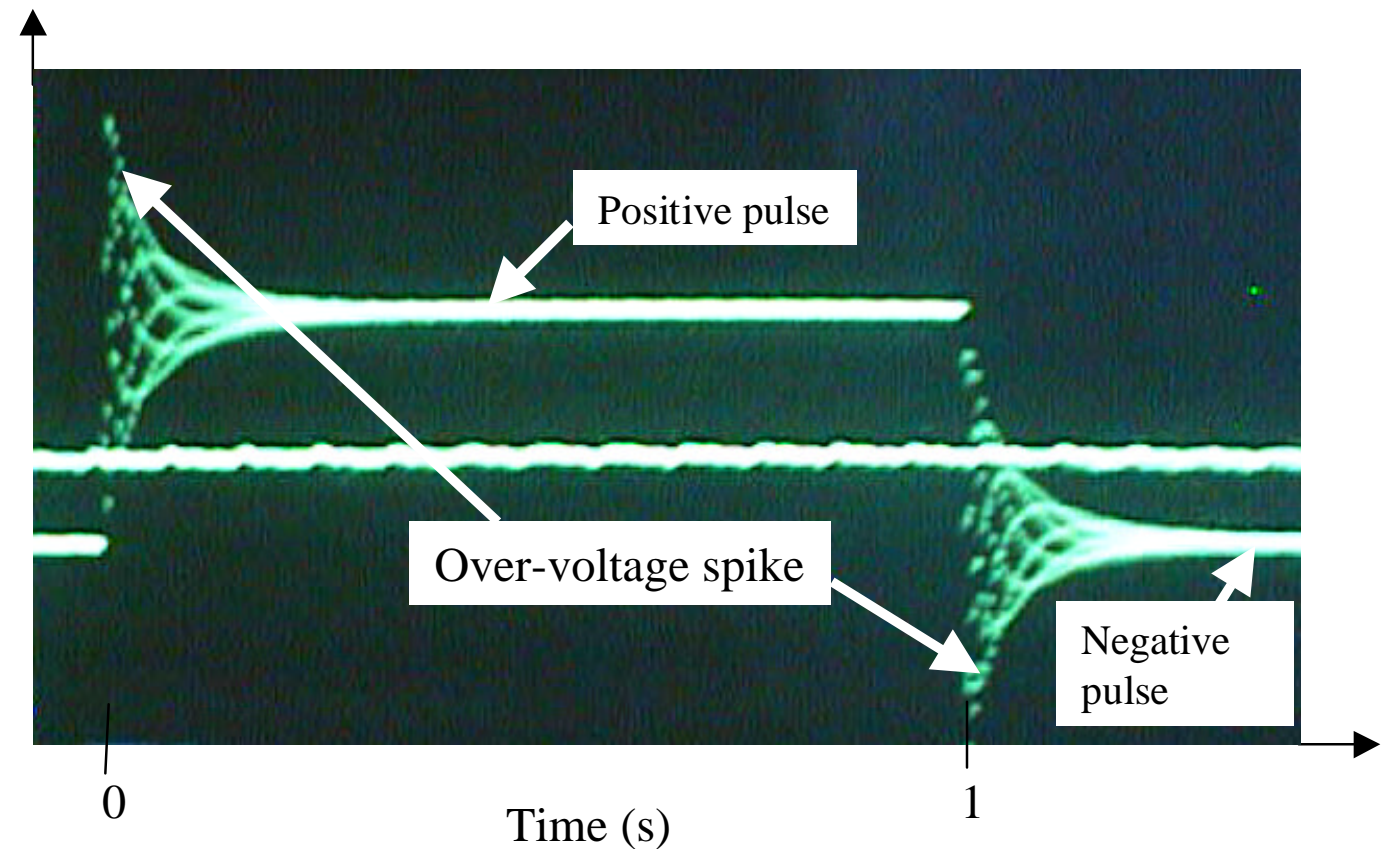

Figure 5. Transient behavior of a 10,000-ohm resistor using a square-wave voltage pulse. Large voltage overshoots are observed in the oscilloscope traces. 